\title{
Eye bank issues: II. Preservation techniques: warm versus cold storage
}

\author{
Pels Elisabeth • Beele Hilde · Claerhout Ilse
}

Received: 8 February 2007/ Accepted: 28 March 2007/Published online: 16 May 2007

(C) Springer Science+Business Media B.V. 2007

\begin{abstract}
Most of the tissue used for penetrating keratoplasty is issued through eye banks that store the corneoscleral button either in hypothermic storage at $2-6^{\circ} \mathrm{C}$ or in organ culture at $31-37^{\circ} \mathrm{C}$.

These two preservation techniques differ in technical aspects, tissue evaluation possibilities, storage time and microbiological safety. Hypothermic storage is simple and requires little expensive equipment. In general a pre-storage evaluation of the endothelium is performed by specular microscopy and storage time is usually around 7-10 days. Organ culture is a relatively complicated technique requiring more expertise and well-equipped facilities. Evaluation of the endothelium is not only performed before storage, but is routinely performed after storage through the use of light microscopy. With organ culture the allowed storage period is longer, up to four weeks. The vulnerability of organ culture to microbial
\end{abstract}

P. Elisabeth

Cornea Bank Amsterdam, Netherlands Institute for

Neuroscience, Meibergdreef 47, 1105 BA Amsterdam,

The Netherlands

B. Hilde

Tissuebank, Ghent University Hospital, De Pintelaan 185, 9000 Ghent, Belgium

\section{Ilse $(\square)$}

Department of Ophthalmology, Ghent University Hospital, De Pintelaan 185, 9000 Ghent, Belgium

e-mail: Ilse.Claerhout@UGent.be contamination can be turned into an advantage because it allows the detection of residual micro-organisms on the cornea before surgery. Both preservation techniques seem to result in similar graft survival.

The method of choice for preservation of the donor cornea is dictated by a number of factors mentioned in this review and this helps to explain the geographical differences in the use of the different techniques.

Keywords Organ culture - Hypothermic storage · Eye banking

\section{Introduction}

Throughout the world post-mortem eye tissue is used for keratoplasty. The generally accepted storage method for the whole globe is the "moist chamber"; a moistened pot at $2-6^{\circ} \mathrm{C}$ introduced in 1935 [1]. The corneoscleral button is stored in tissue culture medium, either in the hypothermic storage method at $2-6^{\circ} \mathrm{C}$ introduced in 1974 [2] or in the organ culture method at $31-37^{\circ} \mathrm{C}$ introduced in 1976 [3]. Corneas cannot reliably be frozen.

The prevailing storing technique today is the storage of the corneoscleral button. The storage time can be extended by removing the corneoscleral button from the globe. A longer storage time permits greater flexibility in the use of the donor tissue and prevents wastage. In addition in many countries, for different reasons, legal or ethical, corneoscleral disc 
excision in situ is preferred to the removal of the whole globe. Moreover, the preparation of lamellae and mushroom-shaped grafts from a corneoscleral button is nowadays possible with help of an artificial anterior chamber. With the introduction of the preservation media, corneal surgeons have to rely on highly skilled technicians employed in eye banks selecting and storing the donor tissue.

The original hypothermic storage solution, the $\mathrm{M}-\mathrm{K}$ medium, has been succeeded by other solutions claiming better and longer maximum storage results. The hypothermic method is common all over the world.

Although organ culture originates from the United States $[3,4]$ it has been strongly promoted by the Eye Bank of Arrhus in Denmark [5, 6] and is now widely applied in Western Europe but not commonly used elsewhere. After some modifications shortly after its introduction the organ culture storage technique has stayed the same. The storage media became commercially available although some eye banks still prefer to prepare them themselves. They differ slightly in composition between banks and countries [7].

Both storage methods, hypothermic and organ culture will be compared considering technical aspects, tissue evaluation possibilities, storage time, microbiological safety, graft survival and future applications with regard to the increased interest in lamellar grafting.

\section{Technical aspects}

\section{General}

Procurement and storage techniques have to be performed under aseptic conditions. Increasingly, eye banks have a formally established quality assurance program.

This and the increasing regulation may affect banks working on a smaller scale. For example in France the number of operating eye banks reduced form 226 in 1993 to 43 in 2004.

\section{Hypothermic storage}

The technique is simple: refrigerator storage with minimal handling. It requires no complex or expensive equipment. The storage solutions are commercially available and manufacturer recommendations should be followed for temperature, maximal storage time, expiry date and other factors. The vials may allow inspection of the endothelium by specular microscopy (Fig. 1 left). During storage the cornea remains thin and, provided donor screening permits release of the tissue, it is directly available for surgery.

The medium consists of a tissue culture medium, supplemented with antibiotics, deturgescent agents like dextran and chondroitin sulphate to prevent corneal swelling in vitro, and other additives such as energy sources, antioxidants, membrane stabilizing and growth factors to improve the storage capacity. Inspection of the tissue by slit-lamp and/or specular microscope can be performed in a closed system.

Organ culture

The technique is relatively complicated, despite the fact that nowadays the storage solutions are commercially available.

The corneas are stored in an incubator at $30-37^{\circ} \mathrm{C}$ in a tissue culture medium, supplemented with fetal or newborn calf serum, antibiotics and antimycotics (Fig. 1 right). Dehydrating macromolecules, necessary to maintain normal hydration in vitro, are ingested by the corneal cells at a physiological temperature and found accumulated in vacuoles in the cells and layers of the cornea [8, 9]. Therefore they are omitted from the storage solution. As a result the cornea swells to about twice its normal thickness during storage. The swelling should be reversed before transplantation. This is performed by placing the cornea in the storage medium supplemented with dextran. This so-called transport medium is also used for the transport of the cornea at room temperature. The extent of deswelling depends on the dextran concentration, varying from $4-8 \%$ in the different banks, resulting in a thickness of about 0.5 to $0.7 \mathrm{~mm}$, depending on the preference of the surgeon(s) using the tissue from a certain bank. The maximum time the cornea spends in the transport medium also varies between banks; from less than one up to seven days $[7,8]$. The risk of the ingested dextran in relation to the export area and transport time is judged differently.

Depending on the media used, renewal of the medium occurs after 10-14 days of storage [7]. For 
Fig. 1 Corneoscleral buttons in different vials for hypothermic storage (left) and in the incubator during organ culture (right)

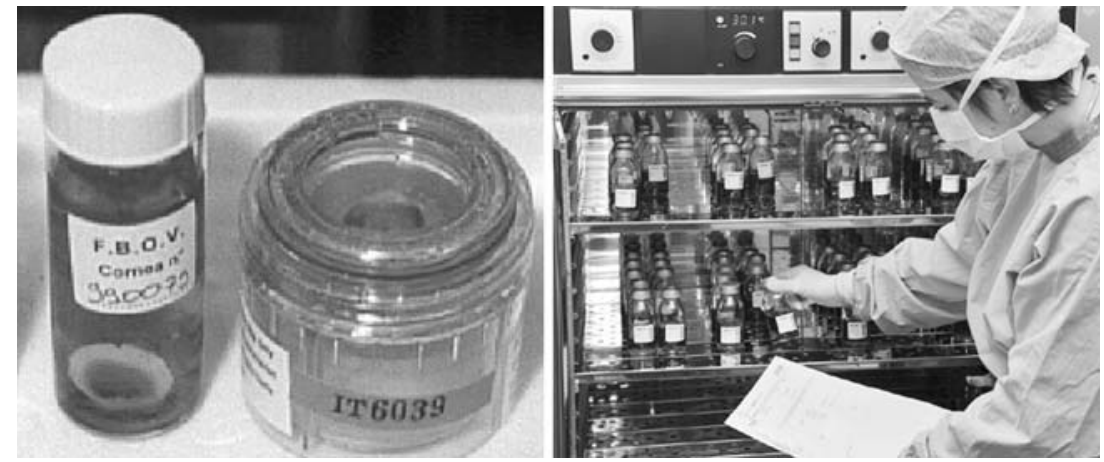

inspection of the endothelium, mandatory after storage, an invasive technique has to be used, which has to be performed under strict aseptic conditions.

The necessary transfer of the cornea from the storage to the transport solution averts a stored cornea from being directly available for use. Besides, a minimal storage period is required for microbiological testing. All this makes the technique more complicated than the hypothermic storage method.

\section{Tissue evaluation}

\section{General}

Irrespective of the storage method(s) used the donor should be adequately screened. Tissue that is potentially hazardous to eye bank personnel and the recipient should be excluded in addition to tissue that poses a risk for the success of the surgery. Physical assessment, serologic testing and evaluation of medical and social history of the donor are mandatory.

Routine inspection of the endothelium is also part of the donor evaluation. Moreover, it can play an important role in setting higher and more-uniform quality standards for tissue acceptance. It may also help to increase the donor supply by assessing corneas that may otherwise be arbitrarily excluded for transplantation on the basis of age or time post mortem. The possibilities for evaluation of the endothelium are dependent of the storage method used.

Studies linking graft outcome with morphometric parameters of solely the endothelium are still lacking. A model has been presented to calculate endothelial cell loss in the long run of 10-20 years after penetrating keratoplasty [10]. In this way it is possible to predict when cell density would reach levels that are incompatible with maintenance of transparency and graft function. The model provides a rationale for the setting of minimum donor cell densities. However, the definite cut-off points are still at the discretion of the bank and surgeon.

\section{Hypothermic storage}

Determination of endothelial cell density is a standard method of corneal tissue evaluation according to the Medical Standards of the Eye Bank Association of America, effective since December 2001. In general this will be a pre-storage evaluation of the endothelium by specular microscopy (Fig. 2 left). Because the appearance of the endothelial cells varies with temperature, type and time of preservation and media, evaluation at room temperature is recommended. When it is impossible to obtain an endothelial cell count, this requirement may be waived on a case-by-case basis by the Medical Director.

Selection criteria and cut-off points for the morphology of the corneal endothelium are not defined. In most cases only descriptions of the endothelial mosaic are used: swollen cells, dark spots, guttae, lysed cells, mild to severe polymegethism and pleomorphism [11].

Most specular microscopes are equipped with software programs to determine parameters describing the endothelial mosaic in terms of variation in cell shape andthe percentage of hexagonal cells in addition to the assessment of the cell density. The obtained morphometric results may help to standardize descriptions, but only provided the microscopes are well 
Fig. 2 Evaluation of the endothelium by specualr microscopy (left) and light microscopy after artificial swelling of the intercellular space (right)
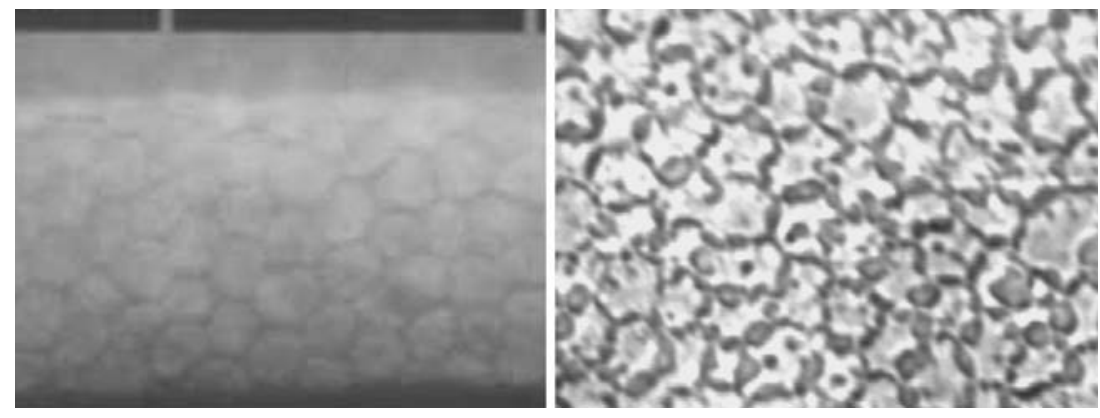

calibrated and the necessary interactive manipulation is performed by an experienced observer.

\section{Organ culture}

After organ culture specular microscopy is not suitable for visualization of the endothelium. Therefore light microscopy is applied, bright field or phase contrast. It is necessary to visualize the endothelial cells by swelling the intercellular space with a hypotonic solution. This allows inspection over the entire endothelial surface (Fig. 2 right). The mechanism has been described by Kirk and Hassard [12] and was worked out for the corneal endothelium by Sperling [13]. Because it is an invasive technique, it must be performed under aseptic conditions. The swelling is transient, it disappears after a couple of minutes and is dependent on the integrity of the cellular membranes. In dead and necrotic cells and in their direct neighborhood swelling will not occur. Before and after storage balanced salt solution (BSS), phosphate buffered saline (PBS), $1.8 \%$ sucrose-PBS mixture or hypo-osmotic BSS may induce swelling, while for tissue in solutions with dehydrating agents a stronger stimulus with $1.8 \%$ sucrose might be necessary [7]. Induction of swelling and the swelling pattern are dependent on storage time and medium [14]. Therefore the interpretation of images requires experience and constant working conditions.

The application of a vital stain such as trypan blue $[15,16]$ preceding the artificial swelling of the intercellular space may help to recognize dead or necrotic cells or denuded Descemet's membrane.

Microscopes should be well calibrated both for manual counting as for evaluation by image analysis programs [17]. These software programs are commercially available, either specifically designed for endothelial evaluation, or as general programs adapted to do this. All programs aim for automated cell analysis that is independent of the observer and experience. However, in general, reliable parameters for the endothelial mosaic are only obtained interactively. This still requires experienced observers. Manual counting by Gunderson's method [18] can provide reliable cell counts [19], but for parameters such as variation in cell size and the percentage of hexagonals image analysis is necessary.

The quality of the corneal stroma can be evaluated by light microscopy. The significance of the presence of lysed keratocytes for the survival of the graft has not yet been investigated [20].

\section{Storage time}

\section{General}

As the endothelium is essential for graft clarity and survival, the maximum allowed storage time is predominantly determined by maintenance of the endothelial function and integrity [21]. Regression lines, coefficients and equations have been published for storage time and damage or loss of endothelial cells. In Fig. 3 the regression lines are collected for different storage methods [22-24]. The referred studies have in common that the vital stain with trypan blue is used to assess endothelial damage. The figure clearly demonstrates the differences in endothelial viability and explains the differences in the allowed maximum storage period.

\section{Hypothermic storage}

The original $\mathrm{M}-\mathrm{K}$ medium claimed a storage period of up to 10 days. Solutions introduced later, such as 


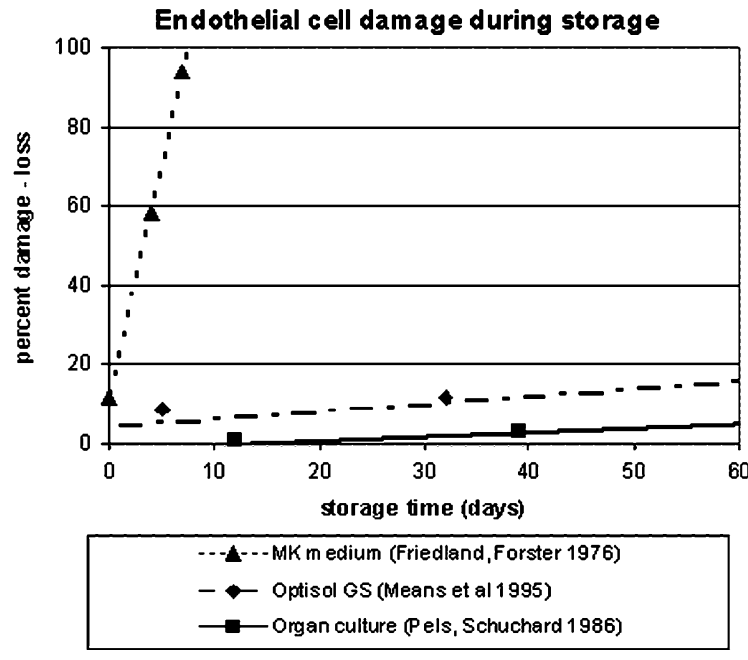

Fig. 3 Regression lines showing endothelial cell damage and loss in different storage solutions assessed after staining with trypan. The regression formulas for the $\mathrm{M}-\mathrm{K}$ medium, the Optisol GS and the organ cultures are respectively: $y=11.8 x+11.6, y=0.19 x+4.2$, and $y=0.11 x-1.8$

the modified M-K medium, K-sol, Dexsol, Likorol, Optisol (Plus, GS) claimed better storage capabilities and a maximum storage period of 14-16 days. Changes in the endothelium as a result of postmortem time and other variables, such as cause of death, donor age, circumstances of death etc., might result in the transplantation of corneas of inferior quality after storage. Because degenerative changes will progress during hypothermic storage, endothelial cell loss has to be taken into account [25], and might even lead to complete cell death. The need for methods to detect corneas not tolerating the prolonged hypothermic storage has therefore been suggested [26]. To reduce the risk of primary graft failure, the recommended storage periods are kept far below the claimed maxima. The applied period increased from 2-3 days for the $\mathrm{M}-\mathrm{K}$ medium [27, 28] up to 7-10 days for Optisol [7, 25]. In addition the time interval from death of the donor to storage of the cornea is generally kept relatively short, within $12 \mathrm{~h}$ or shorter [7].

\section{Organ culture}

With organ culture the allowed storage period is longer. In addition the time interval between death and storage is generally extended to $24-48 \mathrm{~h}$, because significant wound healing can still occur during storage [29].

The loss of endothelial cells during storage may differ between individual corneas (Fig. 4) and is supposed to reflect differences in vitality as a result of post-mortem time and other variables such as cause of death, donor age, circumstances of death etc. In this respect, prolonged hypothermic storage might not be so different from organ culture. Severe endothelial cell loss during organ culture may also be caused by herpes simplex virus infection of the donor tissue [30, 31]. Organ culture is therefore considered a stress test $[32,33]$. A storage period of up to $4-5$ weeks is possible [32-35]. However, in order to detect tissue not tolerating the storage, according to European Eye Bank Rules, inspection of the endothelium after storage is mandatory.

\section{Microbiological safety}

General

Donor eye tissue is usually contaminated [36] and each eye bank has to cope with this. As a first step decontamination procedures are applied before

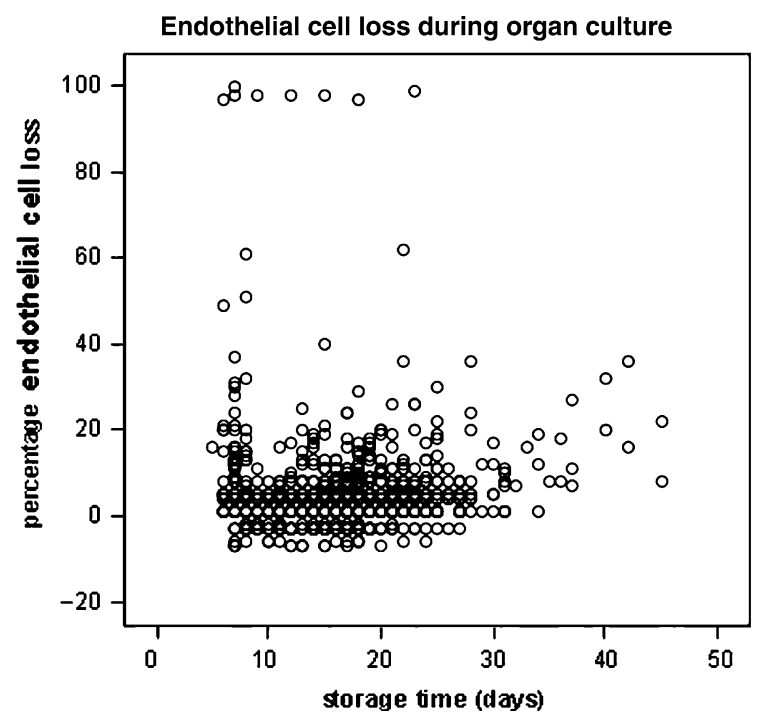

Fig. 4 Percentage endothelial cell loss (endothelial cell density before storage minus the cell density after divided by the cell density before multiplying by 100) during routine storage by organ culture is plotted for a given year 
enucleation or excision of the corneoscleral button. When properly performed these procedures are very effective at reducing the risk of contamination [37]. As a next step, antibiotics, and in the case of organ culture antimycotics, are present in the storage solutions. These are more effective if the contaminating microbes are metabolically active, which means that they are more effective in organ culture than during hypothermic storage. In addition the vulnerability of organ culture to microbial contamination can be exploited to detect microorganisms remaining from the donor and/or introduced into the culture medium by the environment or personnel. Theoretically, in organ culture the risk of contamination is therefore lower than in hypothermic storage.

\section{Hypothermic storage}

Antibiotics have little effect during hypothermic storage. Preoperative warming of the storage media to room temperature is important to enhance the decontamination effect. The optimal time period of room-temperature storage has yet to be established [38]. In addition, antibiotics accumulate in the tissue during storage [39] and become active in the eye after grafting as the temperature rises.

Donor rims tested after grafting are positive for bacteria and fungi in 12-28\% of the cases [40]. However, the value of routine donor rim cultures in clinical use is debated. On the one hand no relevance of infectious complications after keratoplasty has been reported [41, 42]. On the other hand a 22 times increased incidence of endophthalmitis in the case of a positive rim culture [43] to a fully associated fungal infection following penetrating keratoplasty has been described [44]. The overall incidence of postoperative keratitis and endophthalmitis caused by microbes transferred with the donor cornea is low and varies from $0.2 \%$ [43] to $0.41 \%$ [45] and to $1.3 \%$ [46].

The addition of alternative antibiotics to the current hypothermic storage solutions has been suggested, because donor corneas are often removed in hospitals and other settings where resistant bacteria may be thriving [38]. These may cause an increased incidence of endophthalmitis. From a microbiological point of view, however, it is disputable whether the addition of the latest antibiotics with the widest spectra is the best solution.
Organ culture

Contamination detected during organ culture varies between eye banks [7]. This may be dependent on the antibiotic cocktail present in the medium (narrow- to wide-spectrum antibiotics), collection procedures, in situ excision or enucleation and the post-mortem time of collection and storage [47]. Microbiological testing of medium samples before surgery is mandatory as well as a quarantine period before issuing corneas. Microbiological safety of the tissue stored by organ culture is obtained by discarding contaminated tissue before grafting. The incidence of endophthalmitis reported after a properly performed organ culture procedure is $0-0.1 \%$ [7].

Sterility may be better with organ culture since microbial contamination will become more readily evident. Organ culture might be considered as the method of choice in circumstances where corneas are suspected of being at a higher risk of contamination.

The mandatory reporting of adverse reactions and the central registration of these within the EU area where both the hypothermic and the organ culture techniques are used will demonstrate in time whether the incidence of endophthalmitis really differs between organ culture and hypothermic storage.

\section{Graft survival}

Only one prospective study is available comparing clinical results after grafting between the hypothermic storage and organ culture [48]. During the 12 year study period no statistically significant differences in visual acuity, corneal thickness or endothelial cell density were found in keratoconus patients. Bourne [49], however, found fewer endothelial cells after grafting on corneas stored by organ culture. At that time, $\mathrm{M}-\mathrm{K}$ medium was used to reverse the swelling, a method differing from the method used in Europe.

Retrospective studies claim improved [33, 50] or comparable results with organ culture [34, 35, 51]. The improvement is not ascribed to the storage itself but to the extra selections routinely included in organ culture preservation. In addition most of the studies were performed at a time when old-fashioned hypothermic storage methods did not always include inspection of the endothelium. 


\section{Future aspects}

With the advent of new surgical techniques such as lamellar grafting, the issues for eyebanks are also changing. The risk for immunological graft rejection is theoretically lower in lamellar grafting. This may reduce the interest in HLA matching of donor and recipient, an important reason to prefer organ culture as a storage method. Organ culture provides sufficient time for typing and matching and is also thought to immunologically modify the tissue through the loss of passenger leucocytes and epithelium [52].

For a long time stored corneosclereal buttons were used for penetrating keratoplasty whereas lamellar grafting was performed with tissue from whole globes stored in a moist chamber. With the introduction of the artificial anterior chamber, the microkeratome and the intralase or femtosecond laser, this is changing quickly. Corneoscleral buttons which have been precut in order to reduce the manipulation of the donor tissue at the time of surgery will be new products of eye banks. For a reliable production of these precut buttons the intralase or femtosecond laser technique seems very promising [53-55]. Whether the storage technique (hypothermic of organ culture) might affect the postoperative fate of the corneal lamella is still open for discussion.

The revival of the mushroom technique is another development, where the eye bank would be expected to prepare the corneal button [56, 57]. Hypothermic storage, where the thickness of the cornea is maintained and where the risk of epithelial ingrowth is low because there is no epithelial growth, seems to be more suitable for these indications.

\section{Conclusions}

With the more widespread use of the specular microcope and the introduction of hypothermic storage solutions claiming an intermediate storage period some of the advantages ascribed to organ culture [58], such as scheduling operations and minimizing wastage of donor tissue, have become less important. Others still remain: allowing time for tissue typing and matching and extensive testing, detection of residual micro-organisms before surgery, and selecting and dispatching corneas with a well-defined endothelial quality assessed after storage. In addition the pool of possible donors can be enlarged thanks to the possibility of wound healing during organ culture and the inspection of the tissue after storage. Because organ cullture involves extensive testing of the quality of the donor cornea, there are theoretically no preset limits on donor age and postmortem time.

To permit these possibilities the organ culture procedure is more complicated than the hypothermic storage. Well qualified personnel, advice of microbiological laboratory staff, and a well suited facility are essential for a proper organ culture procedure but may also be valuable for hypothermic storage. The higher costs of organ culture have to be balanced against the offered advantages and possibilities not permitted by the hypothermic storage.

Whether organ culture will also be the proper storage technique for surgically manipulated corneoscleral buttons remains to be investigated.

\section{References}

1. Filatov VP (1935) Transplantation of the cornea. Arch Opthalmol 13:321-347

2. Mc Carey BE, Kaufman HE (1974) Improved corneal storage. Investigative Ophthalmol 13:165-173

3. Doughman DJ, Harris JE, Schmitt KM (1976) Penetrating keratoplasty using $37^{\circ} \mathrm{C}$ organ cultured cornea. Trans Am Acad Ophthalmol Otolaryngol 88:778-793

4. Doughman DJ, Harris HE, Mindrup E et al (1982) Prolonged donor cornea preservation in organ-culture: long term clinical evaluation. Cornea: 7-20

5. Sperling S (1979) Human corneal endothelium in organ culture. The influence of temperature and medium of incubation. Acta Ophthalmol 57:269-276

6. Sperling S, Olsen T, Ehlers N (1981) Fresh and cultured corneal grafts compared by post-operative thickness end endothelial cell density. Acta Ophthalmol 59:566-575

7. Maas H, Tullo AB, Pels E (2003) Directory European Eye Bank Association Antwerp Belgium 2006

8. Pels E, Schuchard Y (1984/1985) Corneal preservation and eye banking. The effects of high molecular weight dextran on the preservation of human corneas. Cornea 3:219-227

9. Borderie VM, Baudrimont M, Lopez M et al (1997) Evaluation of the deswelling period in dextran-containing medium after corneal organ culture. Cornea 16:215-223

10. Armitage WJ, Dick AD, Bourne WM (2005) Predicting endothelial cell loss and long-term corneal survival. Investigative Ophthalmol 44:3326-3331

11. Rosenwasser GOD, Nicholson WJ (2003) Introduction to eye banking: a handbook and atlas. Proforma pp 106-117

12. Kirk AH, Hassard DTR (1969) Supravital staining of the corneal endothelium and evidence for a membrane on its surface. Canad J Ophthalmol 4:405-415

13. Sperling S (1986) Evaluation of the endothelium of human donor corneas by induced dilation of intercellular spaces 
and trypan blue. Greafe's Arch Clin Exp Ophthalmol 224:428-434

14. Thuret G, Manisolle C, Herrag S et al (2004) Controlled study of the influence of storage medium type on endothelial assessment during corneal organ culture. $\mathrm{Br} \mathrm{J}$ Ophthalmol 88:579-581

15. Stocker FW, King EH, Lucas DO et al (1970) Clinical test for evaluating donor corneas. Arch Opthalmol 84:2-7

16. Singh G, Böhnke M, von Domarus D et al (1985/1986) Vital staining of corneal endothelium. Cornea 4:80-91

17. Thuret G, Manisolle S, Le Petit JC et al (2003) Is manual counting of corneal endothelial cell density in eye banks still acceptable? The French experience. Br J Ophthalmol 87:1481-1486

18. Gundersen HJG (1977) Notes on the estimation of the numerical density of arbitrary profiles. The edge effect. J microscopy 111(II):219-223

19. Gain P, Thuret G, Chiquet $\mathrm{C}$ et al (2002) Automated analyzer of organ cultured corneal endothelial mosaic. Fr J Ophthalmol 25:462-472

20. Borderie V, Martinache C, Sabolic V et al (1998) Light microscopic evaluation of human donor corneal stroma during organ culture. Acta Ophthalmol Scand 76:154-157

21. Stocker RW (1953) The endothelium of the cornea and its clinical implications. Trans Am Ophthalmol Soc 5:165173

22. Friedland BR, Forster RK (1975) Comparison of corneal storage in Mc Carey-Kaufman medium, moist chamber, or standard eye-bank conditions. Investigative Ophthalmol 15:143-147

23. Means TL, Geroski DH, Hadley A et al (1995) Viability of human corneal endothelium following Optisol-GS storage. Arch Ophthalmol 113:805-809

24. Pels E, en Schuchard Y (1986) Organ culture and endothelial evaluation as a preservation method for human corneas. In: Brightbill FS (ed) Corneal Surgery, 1st edn. Mosby Company, St Louis, pp 93-101

25. Camposampiero D, Tiso R, Zanetti E et al (2003) Improvement of human corneal endothelium in culture after prolonged hypothermic storage. Eur J Ophthlamol 13:745-751

26. Saggau DD, Bourne WM (1989) A comparison of two preservation media (CSM and K-sol) by scanning electron microscopy of preserved corneal endothelium. Arch Ophthalmol 107:429-432

27. Aquavella JV, Van Horn DL, Haggerty CJ (1975) Corneal preservation using $\mathrm{M}-\mathrm{K}$ medium. Am J Ophthalmol 80:791-799

28. Bigar F, Kaufman HE, McCarey BE et al (1971) Improved corneal storage for penetrating keratoplasties in man. Am J Ophthalmol 79:115-120

29. Doughman DJ, Van Horn D, Rodman WP et al (1976) Human corneal endothelial layer repair during organ culture. Arch Ophthalmol 94:1791-1796

30. Cleator GM, Klapper PE, Dennett C et al (1994) Corneal donor infection by herpes simplex virus: herpes simplex virus DNA in donor corneas. Cornea 13:294-304

31. Sengler U, Spelsberg H, Reinhard T et al (1999) Herpes simplex virus (HSV-1) infection in a donor cornea. Br J Ophthalmol 83:1403
32. Pels E, Beekhuis WH, Völker-Dieben HJ (1999) Longterm storage for keratoplasty. In: Brightbill FS (ed) Corneal surgery, 3nd edn. Mosby Company, St Louis, pp $987-$ 906

33. Böhnke M (1991) The Hamburg system of corneal preservation. Klin Mbl Augenheilk 198:562-571

34. Andersen J, Ehlers N (1987) Corneal transplantation using 4 week banked donor material. Long term results. Acta Ophthalmol 65:293-299

35. Frueh BE, Böhnke M (1994) Corneal grafting of donor tissue preserved for longer than four weeks. Cornea 14:463-466

36. Pardos GJ, Gallagher MA (1982) Microbiological communication of donor eyes. Arch Ophthalmol 100:161-165

37. Builles N, Michel P, Reverdy M-E et al (2006) Reducing contamination when removing and storing corneas: a multidisciplinary, transversal, and environmental approach. Cornea 25:185-192

38. Kapur R, Tu EY, Pendland SL et al (2006) The effect of temperature on the antimicrobial activity of Optisol-GS. Cornea 25:319-324

39. Barza M, Baum JL, Kane A (1977) Comparing radioactive and trephine-disk bioassays of dicloxacillin and gentamicin in ocular tissues in vitro. Am J Ophthalmol 83:530-539

40. Farrell PL, Fan JT, Smith RE, Trousdale MD (1991) Donor cornea bacterial contamination. Cornea 19:381-386

41. Wiffen SJ, Weston BC, Maguire LJ et al (1997) The value of routine donor corneal rim cultures in penetrating keratoplasty. Arch Ophthalmol 115:719-724

42. Everts RJ, Fowler WC, Chang DH et al (2001) Corneal scleral rim culturesL lack of utility and implications for clinical decision-making and infection prevention in the care of patients undergoing corneal transplantation. Cornea 20:586-589

43. Leveille AS, McMullan FD, Cavanagh HD (1983) Endophthalmitis following penetrating keratoplasty. Ophthalmol 90:38-39

44. Keyhani K, Seedor JA, Shah MK et al (2005) The incidence of fungal keratitis and ophthalmitis following penetrating keratoplasty. Cornea 24:288-291

45. Antonios SR, Cameron JA, Badr IA et al (1991) Contamination of donor corneas: postpenetrating keratoplasty endophthalmitis. Cornea 10:217-220

46. Kunimoto DY, Tasman W, Rapuano C et al (2004) Endophthalmitis after penetrating keratoplasty: microbiologic spectrum and susceptibility of isolates. Am J Ophthalmol 137:343-345

47. Borderie VM, Lopez M, Laroche L (1997) Donor corneoscleral rim cultures after organ culture. Br J Ophthalmol 81: 513

48. Rijneveld WJ, Beekhuis WH, Van Rij G et al (1982) Clinical comparison of grafts stored in Mc Carey-Kaufman medium at $4{ }^{\circ} \mathrm{C}$ and in corneal organ culture at $31^{\circ} \mathrm{C}$. Arch Ophthalmol 110:203-205

49. Bourne WM, Doughman DJ, Lindstrom RL (1985) Decreased endothelial cell survival after transplantation of corneas by three modifications of corneal organ culture technique. Ophthalmol 92:1538-1541

50. Völker-Dieben HJ, D'Amaro J, Kok-Van Alphen CC et al (1986) E. The survival of organ-cultured donor corneas. In: 
Brightbill FS (ed) Corneal surgery, 1st edn. Mosby Company, St Louis, pp 632-639

51. Redmond RM, Armitage WJ, Whittle J et al (1992) Long-term survival of endothelium following transplantation of corneas stored by organ culture. Br J Ophthalmol 76:479-481

52. Pels E, Van der Gaag R (1984/1985) HLA-A,B,C and HLA-DR antigens and dendritic cells in fresh and organ culture preserved cornea. Cornea 3:231-239

53. Sikder S, Snyder RW (2006) Femtosecond laser preparation of donor tissue from the endothelial side. Cornea 25:416-422

54. Cheng YYY, Pels E, Müller LJ et al (2006) Preparation of posterior lamellar discs (PLD) with femtosecond (FS) laser technology for posterior keratoplasty. Paper presented at the XXIV Congress of the ESCRS, London UK, 10 September 2006
55. Cheng YYY, Pels E, Wijdh RJHJ et al (2006) Femtosecond laser descemet stripping endothelial keratoplasty (FS DSEK) for treatment of corneal disease. Paper presented at the XXIV Congress of the ESCRS, London UK, 10 September 2006

56. Van Rij G (2006) Mushroom graft for penetrating keratoplasty in keratoconus. Paper presented at the European Cornea Conference, Ghent, Belgium, 24-25 June 2006

57. Busin M (2003) A new lamellar wound healing configuration for penetrating keratoplasty surgery. Arch Ophthalmol 121:260-265

58. Pels E (1997) Organ culture: the method of choice for preservation of human donor corneas. Br J Ophthalmol $81: 523-525$ 